\title{
Personality Traits and Emotional Word Recognition: An ERP Study
}

\author{
Li-Chuan Ku ${ }^{1,2,3} \cdot$ Shiao-hui Chan ${ }^{3}$ Vicky T. Lai ${ }^{1,2}$
}

Published online: 26 February 2020

(C) The Psychonomic Society, Inc. 2020

\begin{abstract}
Recent research has investigated how personality trait differences influence the processing of emotion conveyed by pictures, but limited research has examined the emotion conveyed by words. The present study investigated whether extraversion (extroverts vs. introverts) and neuroticism (high neurotics vs. low neurotics) influence the processing of positive, neutral, and negative words that were matched for arousal. Electroencephalography (EEG) was recorded from healthy participants while they performed a lexical decision task. We found that personality traits influenced emotional word recognition at N400 (300-450 ms) and LPC $(450-800 \mathrm{~ms})$. At the earlier (N400) stage, the more extraverted and neurotic a participant was, the more reduced the N400s for the positive words relative to neutral words were. This suggests that the extroverts and high neurotics (i.e., high impulsivity) identified positive content in words during lexical feature retrieval, which facilitated such retrieval. At the later (LPC) stage, both the introverts and high neurotics (i.e., high anxiety) showed greater LPCs to negative than neutral words, indicating their sustained attention and elaborative processing of negative information. These results suggest that extraversion and neuroticism collectively influence different stages of emotional word recognition in a way that is consistent with Gray's biopsychological theory of personality.
\end{abstract}

Keywords Extraversion $\cdot$ Neuroticism $\cdot$ Impulsivity $\cdot$ Anxiety $\cdot$ Emotional words $\cdot$ Event-related potentials

\section{Introduction}

Do people with different personality traits process emotional content in different ways? Two of the personality traits, extraversion (extraverted vs. introverted) and neuroticism (neurotic vs. nonneurotic), have been the focus of many trait theories (Cattell, 1965; Costa \& McCrae, 1992; Eysenck, 1947, 1967). Extraversion and neuroticism form a two-dimensional space that influences a person's motivation and sensitivity to emotional stimuli. In terms of extraversion, extraverted individuals are sensitive to positive cues, such as agreement, compliment, and self-references, and tend to report positive affects in the

Li-Chuan $\mathrm{Ku}$

lchnku@gmail.com

Shiao-hui Chan

shiaohui@ntnu.edu.tw

1 Department of Psychology, University of Arizona, 1503 E University Blvd, Tucson, AZ 85721, USA

2 Cognitive Science Program, University of Arizona, Tucson, AZ, USA

3 Department of English, National Taiwan Normal University, No. 162, Sec. 1, Heping E. Rd., Da-an District, Taipei 106, Taiwan environment (Pennebaker \& King, 1999). In contrast, introverts tend to mute expression of positive affect due to their reserved or reflective characteristics (Morris, 1979). Physiologically, extroverts seek excitement and social interactions to heighten their reticulothalamic-cortical arousal level, while introverts tend to avoid social interactions in an effort to keep such cortical arousal to a minimum (Eysenck \& Eysenck, 1985; Watson \& Clark, 1997). In terms of neuroticism, neuroticism is associated with emotion instability and the sensitivity to negative stimuli, such as anxiety, depression, or anger (John, Naumann, \& Soto, 2008; Watson, Clark, \& Harkness, 1994). Neurotic people are characterized by an increase of reactivity to the limbic system that is sensitive to emotionally arousing stimuli, with its level affecting the tendency of affective reactivity and emotion regulation (Eysenck \& Eysenck, 1985).

Recent neuroanatomical studies using pictures support the impact of these two personality traits on emotion processing. Neurally, extraversion is positively correlated with the volume of medial orbitofrontal cortex, a brain region involved in processing reward information, whereas neuroticism is negatively correlated with the volume of hippocampus, which are associated with threat, punishment, and negative emotion (DeYoung et al., 2010; Wright et al., 2006). Several imaging studies using pictorial stimuli also revealed differential brain 
involvement in emotion perception/regulation depending on personality traits. For example, extraversion is correlated with responses to positive pictures in the inferior, middle and superior frontal gyri, the cingulate gyrus, the inferior and middle temporal gyri, the basal ganglia, and the amygdala, whereas neuroticism is correlated with increased medial prefrontal response to negative pictures but decreased orbitofrontal cortex (OFC) and right temporal lobe responses to positive pictures (Canli, 2004; Canli et al., 2001; Kehoe, Toomey, Balsters, \& Bokde, 2012). These findings support Gray's biological theory of personality (Gray, 1981), in which extraversion is associated with the behavioral activation system (BAS), and neuroticism with the behavioral inhibition system (BIS). BAS is hypothesized to be sensitive to reward stimuli or incentives, whereas BIS is activated by stimuli of punishment and nonreward. The two systems are negatively correlated, indicating an association between personality traits and emotion: BAS may be more motivated by the need to achieve positive rewards than the need to avert negative outcomes, whereas BIS shows a reversed pattern.

Language is a common way to communicate emotions in daily life, but few studies have explored how personality traits affect the recognition/comprehension of emotional words. Words differ from pictures in many ways. Words name generic types, and pictures display a specific instance of a type (Lai, Hagoort, \& Casasanto, 2012). Words may require more cognitive resources, and pictures may be visually salient and/or processed more rapidly (Wood, Lupyan, \& Niedenthal, 2016). Importantly, words are assumed to be less perceptually complex than pictures, which may lead to different emotional significance influenced by biological preparedness of an individual (Kissler, Assadollahi, \& Herbert, 2006).

Only a handful of behavioral studies examined the influences of extraversion and neuroticism on emotional word processing. Borkenau, Paelecke, and Yu (2010) found that extroverts identified pleasant words faster than neutral or unpleasant words, suggesting that pleasant concepts are more accessible in extroverts. Matthews, Pitcaithly, and Mann (1995) found that both neurotic and non-neurotic individuals showed larger priming effects for negative prime-target pairs than positive pairs. But when the prime-target pairs were neutral words, the neurotic group showed a stronger priming effect than the non-neurotic controls. This suggests that the attention bias to negative word pairs may extend to neutral ones in neurotics, highlighting the bias shift on valence processing in a pre-attentive way. It is, however, unclear when personality traits start to bias valence processing through the aforementioned behavioral studies. Neurophysiological studies have better temporal resolution and can shed light on the issue. Before discussing such results, a brief review on the electrophysiological correlates of emotional words is needed.

Early event-related potential (ERP) effects as early as $\sim 100 \mathrm{~ms}$ (e.g., P1 and N1) have been reported in response to emotional words, albeit with mixed results (Herbert, Junghöfer, \& Kissler, 2008; Herbert, Kissler, Junghöfer, Peyk, \& Rockstroh, 2006; Hofmann, Kuchinke, Tamm, Võ, \& Jacobs, 2009; Palazova, Mantwill, Sommer, \& Schacht, 2011; Scott, O’Donnell, Leuthold, \& Sereno, 2009). It is suggested that the P1 and N1 may be generated in left occipitotemporal areas, including the middle temporal gyrus and the fusiform gyrus, which reflect the link between the detection of visual emotion stimuli and the acquisition of conditioned responses (Hofmann et al., 2009; LeDoux, 2003). However, these early emotion effects may be highly dependent on word frequency (Scott et al., 2009).

A second ERP component often associated with emotional words is the early posterior negativity (EPN), which peaks between 200 and $300 \mathrm{~ms}$ after stimulus onset. EPN has an occipito-temporal scalp distribution and its amplitudes are typically larger for emotionally valenced (positive and negative) words than for neutral words (Citron, Weekes, \& Ferstl, 2013; Herbert et al., 2008; Hinojosa et al., 2010; Hofmann et al., 2009; Kissler, Herbert, Winkler, \& Junghöfer, 2009; Palazova et al., 2011; Recio, Conrad, Hansen, \& Jacobs, 2014; Sass et al., 2010; Schacht \& Sommer, 2009a, b; Scott et al., 2009). Researchers have postulated two possible functional significances for the EPN: (1) automatic processing of emotional stimuli or (2) selective attention. Some associated EPN with an initial, automatic processing of emotional stimuli that is perhaps arousal-driven, because it is not modulated by the tasks or depths of processing (Kissler et al., 2006; Schacht \& Sommer, 2009a). In this time window, source analyses showed that emotion can facilitate the mapping of the visual stimulus with its corresponding lexical representation, as reflected by enhanced activities in the visual word form area for emotional words (Schacht \& Sommer, 2009a). Others associated EPN with selective attention, selectively orienting the readers toward emotion without distinguishing valence and arousal dimensions in this stage (Citron, 2012).

In the similar time window as the EPN, P2 can sometimes be found over fronto-central sites during emotional word processing (Begleiter \& Platz, 1969; Begleiter, Porjesz, \& Garozzo, 1979; Bernat, Bunce, \& Shevrin, 2001; Schacht \& Sommer, 2009b; Schapkin, Gusev, \& Kuhl, 2000). Emotional words typically elicited larger P2 than neutral ones, but not all the studies reported the P2 effects. For instance, Kanske and Kotz (2007) presented positive, negative, and neutral nouns in the right and left visual fields in a lexical decision task and found greater P2 for positive than neutral stimuli, indicating a positive offset under low levels of arousal input. In contrast, Carretié et al. (2008) showed no P2 elicitation using insults, compliments, and neutral adjectives in a same task. Generally, P2 effects can be associated with automatic processing of emotion regardless of the depths of word processing, such as passive viewing (Begleiter \& Platz, 1969), subliminal presentation (Bernat et al., 2001), lexical decision tasks (Kanske \& 
Kotz, 2007; Schacht \& Sommer, 2009b), or affective evaluation tasks (Begleiter et al., 1979; Herbert et al., 2006).

Another component associated with emotional word processing is N400, which peaks around $300-500 \mathrm{~ms}$ and is often anteriorly distributed in such studies (Imbir, Spustek \& Zygierewicz, 2016; Kanske \& Kotz, 2007; Palazova et al., 2011; Recio et al., 2014; Sass et al., 2010). Neutral words tended to elicit greater N400s than both positive and/or negative ones during word processing. For instance, Kanske and Kotz (2007) reported a larger N400 to neutral words than both positive and negative words, with the effect more pronounced in concrete nouns than abstract nouns. The (frontal) N400 has been associated with the facilitated activation of the features of the lexical item from the semantic memory and the word recognition stage of processing (Kutas and Federmeier, 2011). Such an attenuated N400 to emotional words suggests that these words are semantically grouped in the mind to facilitate semantic processing.

The most commonly seen ERP component in emotional word studies is a late positivity component (LPC). It peaks between 500 and $800 \mathrm{~ms}$ and has a centro-parietal scalp distribution. In some cases, the LPC extends several hundred milliseconds, forming a sustained slow positivity peaking between 700 and 1,000 ms. Emotionally valenced words elicited a larger LPC than neutral words (Carretié et al. 2008; Citron et al., 2013; Herbert et al., 2008; Hinojosa et al., 2010; Hofmann et al., 2009; Kanske \& Kotz, 2007; Palazova et al., 2011; Schacht \& Sommer, 2009a, b; Zhang et al., 2014). For example, the LPC was larger for unpleasant words than for neutral and positive words (Kanske \& Kotz, 2007). This is termed "negativity bias," according to which people attend more to negative stimuli than positive ones when salient features, such as word frequency and arousal, are matched. As a part of a larger P3 family, LPC may reflect the reallocation of attention toward an elaborative evaluation of emotional features in the stimulus. However, the negativity bias can be attenuated or even shifted to a positivity bias due to word concreteness or categories (i.e., verbs, adjectives, and nouns) (Herbert et al., 2006; Herbert et al., 2008; Kanske \& Kotz, 2007; Kissler et al., 2009; Palazova et al., 2011).

Little work has addressed how personality traits impact emotional word recognition. One such study (Bartussek et al., 1996) presented participants with positive, neutral, and negative adjectives and had them perform either a structural task (word length judgment) or an affective task (valence judgment). Their general findings were that extroverts reacted to emotional adjectives in both tasks, regardless of word valence, while introverts reacted to emotional and neutral adjectives in the affective task. Specifically, extroverts showed a larger $\mathrm{P} 3$ to both the positive and negative adjectives than the neutral ones in both the structural and affective tasks. Task difference was revealed in the scalp distribution of the P3 effects, namely, a posterior P3 effect in the structural task and a frontal-posterior P3 effect in the affective task. In contrast, introverts showed a posterior P3 effect for the emotional relative to the neutral adjectives, accompanied by a frontal $\mathrm{P} 3$ effect for the negative and neutral adjectives relative to the positive ones, in the affective task only. The authors suggested that the posterior $\mathrm{P} 3$ reflects cognitive processing and that the frontal P3 reflects the processing of emotional valence, possibly the attention reallocation to valence information. Interestingly, neuroticism did not modulate the P3. One caveat was that word arousal might not have been well controlled in Bartussek's et al. (1996) study, which could explain the extraversion modulation of $\mathrm{P} 3$ effects.

Because of the lack of studies on personality and emotional words, we will briefly review studies on personality and emotional pictures to gain an insight of what we expect in the ERPs. Yuan et al. (2012) manipulated emotional valence of pictures (i.e., highly/moderately positive, highly/ moderately negative) in a visual oddball paradigm. Extroverts showed a larger P2 (140-200 ms) and P3 (330$460 \mathrm{~ms}$ ) in response to all the positive pictures than ambiverts, a group of non-extraverted and non-introverted individuals. In contrast, ambiverts showed a larger EPN (220-300 ms) and P3 to the moderately negative pictures than extroverts. In Speed et al. (2015), high extraversion was also associated with a larger LPC (300-1,000 ms) in viewing both the positive and negative pictures. However, no LPC effect was observed for low extraversion or neuroticism. The inconsistent results in these two studies may arise from the samples they chose. The former recruited undergraduate students that were aged 19-29 years, whereas the latter, female adolescents that were aged 13.5-15.5 years. Nevertheless, they provided electrophysiological indices of possible influences from personality traits on emotion processing.

To summarize, studies on emotional words reported the ERP components: P1/N1, P2/EPN, N400, and LPC. The LPC was the most reliably found among them, indexing attention reallocation towards emotional contents. Personality traits mainly modulated P3s during emotional word recognition: frontal P3s are associated with an enhanced attention to valence information, while parietal $\mathrm{P} 3 \mathrm{~s}$, cognitive processing. More informative reports on the influence of personality traits came from emotional picture processing. The P2/EPN, P3, and LPC could all be modulated: early P2 and EPN effects reflected the amount of early attention allocated to biologically significant stimuli, whereas later P3s/LPCs, the cognitive evaluation of stimulus meaning.

In the current study, we examined the time course of influences of extraversion and neuroticism on the visual recognition of emotional words. The study is novel because of its focus on words. Little research had examined the impact of personality on emotional words. We chose the extraversion and neuroticism traits, as implicative in positive and negative emotions, to examine whether and how semantic processing 
and affective responses could be influenced by each trait respectively (i.e., Eysenck's personality model) or collectively (i.e., Gray's BAS/BIS). Participants did a self-paced, lexical decision task, where they decided whether a letter string was a word or a nonword. We expected that extraversion would modulate P3 or LPC based on Bartussek et al. (1996), Yuan et al. (2012), and Speed et al. (2015). Specifically, extroverts would show a larger P3 or LPC in response to positive words compared with negative, due to their enhanced attention to positive emotions. In contrast, introverts would show an enhanced P3 or LPC for negative words than positive. In the N400 time frame, we predicted a smaller N400 for positive words in extroverts and/or negative words in introverts, due to the ease of semantic information retrieval in certain types of valence words. For neuroticism, because previous studies often showed null effects, we do not have a strong expectation and would explore the effects, if any, in emotional words. We believe the study could shed light on the interrelationship between personality traits and semantic/affective processing.

\section{Methods}

\section{Participants}

Forty-two native Mandarin speakers ( 23 males), aged between 20 and 40 (mean age $\pm \mathrm{SD}=26.24 \pm 4.86$ ) years, participated in the experiment for payment. They were recruited through online advertisements in Taipei, Taiwan. Some of them (43\%) had college degrees, and others were undergraduate students. All were healthy, right-handed, and had normal or correctedto-normal vision. These participants had no neurological disorders or psychiatric illness. They gave informed consents in accordance with the local ethics committee prior to participation.

We ensured that the participants were non-depressive using the Beck Depression Inventory-second edition (BDI-II). The BDI-II is a self-report, 21-item questionnaire that measures levels of depression with 4-point scales ranging from 0 to 3 based on severity of each item (Beck, Ward, Mendelson, Mock, \& Erbaugh, 1961). It has good reliability and validity in both the college student and patient samples. The internal reliability (Cronbach's $\alpha$ ) is 0.92 for clinical patients and 0.93 for college students, with the test-retest reliability being 0.93 . The total score ranges from 0 to 63 , with the suggested cutoff score for mild depression being 16 (Lu, Che, Chang, Shen, 2002). Overall our participants' mean BDI-II total score is 5.45 $(\mathrm{SD}=5.05)$, suggesting that they are non-depressive. Data from four participants were excluded from the analysis due to a high BDI-II score (i.e., score $>16$; $\mathrm{N}=1$ ) and excessive artifacts in the EEG data $(\mathrm{N}=3)$.

\section{Personality measures}

We measured extraversion and neuroticism using a short-scale edition of the Eysenck personality questionnaire revised (EPQ-R, Eysenck, Eysenck, \& Barrett, 1985). The EPQ-R is a self-report, 48-item questionnaire that can measure levels of extraversion and neuroticism on scales ranging from 0 to 12 , with 0 indicating the lowest and 12 the highest level of that trait. It has good reliability and validity in the adult sample. The Cronbach's $\alpha$ for the scale of extraversion is $0.84-0.88$, and for the scale of neuroticism, $0.80-0.84$. The participants were first categorized into extroverts versus introverts $(\mathrm{N}=19$ each), based on the median scores on the extraversion $($ median $=6.5$, mean $=6.13, \mathrm{SD}=4.17$ ) subscale in EPQ-R. Then, all of the participants were again categorized into high versus low neurotics ( $N=19$ each), according to the median scores on the neuroticism $($ median $=4.5$, mean $=$ $5.58, \mathrm{SD}=3.96$ ) subscale. The characteristics of the participants included in the final analysis are presented in Table 1. Participants' extraversion and neuroticism scores were negatively correlated $(r=-0.479, p=0.002)$. That is, the more extraverted an individual was, the less neurotic the individual was. We did not focus on psychoticism in this study, because it is more linked to psychopathy, such as schizophrenia in Eysenck et al.'s (1985) personality model, and we focused only on healthy populations in our study.

\section{Materials}

The word stimuli in the EEG experiment consisted of 108 positive words, 108 negative words, and 108 neutral words in Mandarin Chinese (Table 2), and each word type contained 36 adjectives, 36 nouns, and 36 verbs to cover both the emotive words and emotionally valenced words. The selection process is detailed as follows. We started with 1,040

Table 1 Demographic information, BDI-II, and EPQ-R scores of participants

\begin{tabular}{lllll}
\hline & Extroverts & Introverts & $\mathrm{t}$ & $p$ \\
Sex (Male: Female) & $8: 11$ & $11: 8$ & $\mathrm{n} / \mathrm{a}$ & $\mathrm{n} / \mathrm{a}$ \\
Age & $26.58(4.68)$ & $24.74(3.73)$ & -1.340 & 0.189 \\
BDI-II & $3.58(4.02)$ & $5.37(3.73)$ & 1.423 & 0.163 \\
EPQ-R: & $9.89(1.66)$ & $2.37(1.77)$ & -13.506 & $<0.001$ \\
$\quad$ Extraversion & & & & \\
EPQ-R: Neuroticism & $4.11(3.97)$ & $7.05(3.44)$ & 2.446 & 0.019 \\
& & & & \\
Sex (Male: Female) & $10: 9$ & $9: 10$ & $\mathrm{n} / \mathrm{a}$ & $\mathrm{n} / \mathrm{a}$ \\
Age & $24.32(3.61)$ & $27.00(4.57)$ & 2.010 & 0.052 \\
BDI-II & $5.32(3.97)$ & $3.63(3.80)$ & 0.863 & 0.190 \\
EPQ-R: & $4.21(3.85)$ & $8.05(3.63)$ & 0.849 & 0.003 \\
$\quad$ Extraversion & & & & \\
EPQ-R: Neuroticism & $9.05(2.17)$ & $2.11(1.41)$ & -11.693 & $<0.001$ \\
\hline
\end{tabular}


Table 2 Characteristics of the word stimuli used in the lexical decision task

\begin{tabular}{llll}
\hline Mean (SD) & Word & & \\
\cline { 2 - 4 } & Positive & Neutral & Negative \\
\hline $\begin{array}{l}\text { Valence } \\
\quad \text { range }-3 \text { to +3) }\end{array}$ & $1.54(0.27)$ & $-0.03(0.39)$ & $-1.71(0.28)$ \\
$\begin{array}{l}\text { Arousal (range 1 to 7) } \\
\text { Imageability }\end{array}$ & $3.93(0.41)$ & $3.25(0.63)$ & $4.02(0.33)$ \\
$\quad$ (range 1 to 7) & $4.21(0.96)$ & $4.38(1.09)$ & $4.39(0.84)$ \\
$\begin{array}{l}\text { Word Frequency }\left(1 / 10^{9}\right) \\
\text { Orthographic }\end{array}$ & $17804(42202)$ & $20080(64482)$ & $7539(20592)$ \\
$\begin{array}{l}\text { Neighborhood Size } 1^{\mathrm{a}} \\
\text { Orthographic }\end{array}$ & $51.31(61.33)$ & $54.88(49.73)$ & $41.31(60.81)$ \\
Neighborhood Size 2 & $53.39(66.10)$ & $54.01(64.25)$ & $46.32(70.31)$ \\
\hline
\end{tabular}

${ }^{a}$ Orthographic neighborhood size 1 denote the number of neighbors sharing the first constituent (e.g., 平*) character of the word stimulus (e.g., 平 淡, calm).

${ }^{\mathrm{b}}$ Orthographic neighborhood size 2 denote the number of neighbors sharing the second constituent (e.g., *淡) character of the word stimulus (e.g., 平淡, calm)

emotional word stimuli based on two sources: (1) the Chinese emotion word database (Cho, Chen, \& Cheng 2013), which consisted of 613 words that denote emotion states or elicit emotions, and (2) the Chinese Linguistic Inquiry and Word Count (LIWC) dictionary, which consisted of 427 Affect words that refer to or induce emotion processes (Huang et al., 2012). Then, we excluded repetition and words that have both emotional and non-emotional meanings: e.g., bā guà means both gossip and the Eight Trigrams. The exclusion was conducted based on Chinese Gigaword Corpus (Huang, 2009) implemented in Chinese Word Sketch Engine (Huang et al., 2005). After the exclusion, we conducted three pretests on the remaining 750 words and collected ratings for these words along the valence $(-3=$ negative to $3=$ positive $)$, arousal $(1=$ low arousing to $7=$ high arousing $)$, and imageability dimension $(1=$ hardly imageable to $7=$ very imageable $)$. A total of 279 college students participated in the pretests online.

Based on the ratings, we selected 108 positive words (e.g., yú kuài, joyful; gǔ lì, encourage; hūn lǐ, wedding), 108 negative words (e.g., bēi fèn, grievous; rě năo, irritate; xiăo tōu, thief), and 108 neutral words (e.g., píng dàn, calm; xuăn qŭ, select; yè wăn, night). Confirming the experimental manipulation, we found a main effect of valence (positive, neutral, negative) $(F(2,321)=2843.71, p<0.001)$ : positive words scored higher on valence ratings than neutral words, followed by negative words (all $p$ values $<0.001$ ). There was a main effect of arousal $(F(2,321)=83.25, p<0.001)$, which came from the higher arousal ratings for positive/negative words than for neutral words (both $p$ values $<0.001$ ). Positive words were rated as similarly arousing as negative words $(p=0.241)$. We also controlled for imageability ratings. There was no difference in imageability ratings across the three word types $(F(2,321)=1.219, p=0.297)$.

All the word stimuli were further matched for word frequency $(F(2,321)=2.27, p=0.105)$, word length ( 2 characters), and orthographic neighborhood sizes (both $F \mathrm{~s}(2,321) \leq$ $1.613, p \mathrm{~s} \geq 0.201)$. The numbers of the orthographic neighbors, defined as the number of words that can be created by only sharing the first constituent (neighborhood size 1), or the second constituent (neighborhood size 2) characters, were computed by using python-based Load and Analysis Chinese Corpus-Natural Language Toolkit (LACC-NLTK) based on Academia Sinica Balanced Corpus (Chen, Huang, Chang, \& Hsu, 1996). The stimulus characteristics are presented in Table 2.

In addition to word stimuli, 324 Chinese pseudowords were created by repairing the characters randomly in the word condition to form meaningless two-character compounds. The pseudowords followed the phonological and orthographic rules in Chinese. All the 648 words and pseudowords were divided into four lists. Each list consisted of 81 words (27 positive, 27 neutral, 27 negative) and 81 pseudowords. The items within a list were randomized. The order of the lists was counterbalanced with participant number to avoid list effects.

\section{Procedure}

Participants first completed a demographic questionnaire about their health condition, educational background, handedness, and language use. They then underwent the EEG capping procedure. An elastic cap mounted with 32-channel Ag/ $\mathrm{AgCl}$ electrodes was fitted on the participant's head. After capping, the participant was taken to a sound-proofed booth and seated at a desk facing computer screen $80-100 \mathrm{~cm}$ in front of them. The words were presented visually in bold white characters (Font: Courier New; point size: 18; visual angle: $1.25-1.6^{\circ}$ ) on a black background presented via Eprime 2.0 software (Psychology Software Tools, Inc.).

An example trial is illustrated in Fig. 1. Each trial started with a central fixation cross for $500 \mathrm{~ms}$, followed by a blank screen for $200 \mathrm{~ms}$. A target stimulus then appeared at the center of the screen and remained there for 1 second, where the participants were to read the word carefully and silently and decide whether it was a word or a pseudoword. Following the word was a question mark, and the participants had to respond by pressing the YES or NO button on a response box. We asked participants to delay their response until the question mark appeared to avoid motor artifacts in the EEG recording induced by finger movement. The button configuration (left or right) was counterbalanced across participants. After the response, a blank screen with a jitter of 1,500$2,000 \mathrm{~ms}$ was presented, during which participants could blink. 


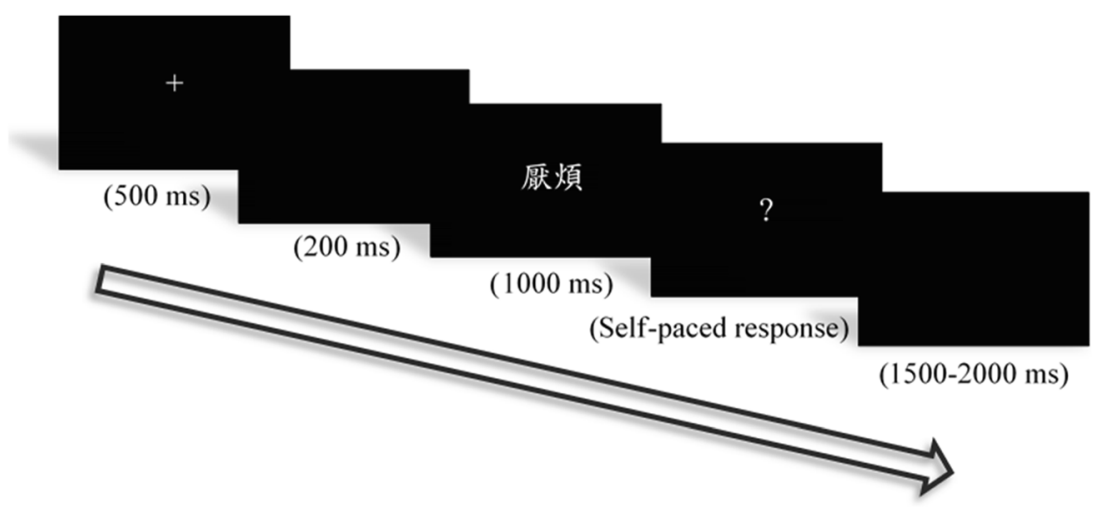

Fig. 1 An example of a trial with a word stimulus 厭煩 (bored) in the lexical decision task

Participants did ten practice trials to familiarize themselves with the procedure before the formal experiment. The session was divided into eight blocks, with a short break between blocks. Each block lasted for 6-7 minutes, and the entire session lasted for $\sim 45$ minutes.

\section{EEG acquisition}

The electroencephalogram (EEG) was recorded from 32 electrodes placed on an electrode cap arranged in the international 10-20 system (Pivik et al., 1993). The vertical and horizontal electrooculogram was recorded through two electrodes placed laterally to the left and right eye (labeled HEOL and HEOR) and two electrodes placed above and below the left eye (labeled VEOU and VEOL). Two external electrodes were placed at the left and right mastoids and scalp EEGs were referenced to an average of the right and left mastoids during online recording (NuAmps, Neuroscan, Inc.). Data were recorded with a sampling rate of $1,000 \mathrm{~Hz}$ and amplified with an amplifier rate (gain) of 19, corresponding to an input range of $\pm 131.5 \mathrm{mV}$. To avoid impulse artifacts, the online low pass filter was set to $100 \mathrm{~Hz}$, and the high pass filter was set as DC recording. The electrode impedance was kept below $5 \mathrm{k} \Omega$.

\section{EEG data analysis}

EEG recordings were processed offline with the EEGLAB toolbox (Delorme and Makeig, 2004) and the ERPLAB plugins (Lopez-Calderon \& Luck, 2014) implemented in Matlab (Mathwork Inc.). The four mono-polar channels (HEOL, HEOR, VEOU, and VEOL) were first converted into two bipolar channels (HEOG and VEOG) by linear operations. The continuous EEG files were then epoched by setting the interval as $200 \mathrm{~ms}$ before and $800 \mathrm{~ms}$ after the stimulus onset, with the prestimulus interval of -200 to $0 \mathrm{~ms}$ as the baseline. Then, eye artifacts (blinks and eye movements) were identified using an independent component analysis with the runica.m algorithm implemented in EEGLAB and were subtracted from the ERP data by visual inspection of the component time courses. Trials contaminated with artifacts due to body movements, alpha waves, or peak to peak deflection exceeding $\pm 100 \mathrm{mV}$ were manually rejected before sorting and averaging. Finally, the ERP data were bandpass filtered with frequency values set as $0.1-30 \mathrm{~Hz}, 12 \mathrm{~dB} /$ oct, using Infinite Impulse Response (IIR)-Butterworth filtering, and grand averaged across the participants for different conditions separately.

\section{Statistical analysis}

Accuracy rates for lexical decisions were first calculated for words and pseudowords. To elucidate between-groups differences on the accuracy rates, a three-way repeated ANOVA with the factors of valence (positive, negative, neutral), extraversion (extroverts, introverts), and neuroticism (high neurotics, low neurotics) was conducted. We did not analyze the mean reaction times in the current experiment, as the delayed response of the lexical decision could render similar reaction times across conditions and participants.

For the ERP data, four-way repeated-measures ANOVAs with the same factors of valence, extraversion, neuroticism, and an additional factor of region were conducted on time windows of P2 (160-260 ms), N400 (300-450 ms), and LPC (450-800 ms) post-stimulus. Following conventions in emotional (Hofmann et al., 2009; Kanske \& Kotz, 2007; Schacht $\&$ Sommer, 2009a) and guided by visual inspection of the ERP grand waveforms (Figs 3, 4, and 6), we examined the distribution of the ERP effects by dividing the scalp into six regions of interest: left anterior ( $\mathrm{F} 3, \mathrm{FC} 3)$, left posterior (CP3, $\mathrm{P} 3)$, mid-anterior (FZ, FCZ), mid-posterior (CPZ, PZ), right anterior $(\mathrm{F} 4, \mathrm{FC} 4)$, and right posterior $(\mathrm{CP} 4, \mathrm{P} 4)$ sites. To adjust the degrees of freedom of the F-values for violations of the sphericity assumption, Greenhouse-Geisser correction was applied. The alpha levels were set as 0.05 for all statistic tests and corrected with a false discovery rate of the same level with the Benjamini-Hochberg procedure (Benjamini \& Hochberg, 1995) in all post-hoc comparisons. Only significant effects or interactions involving the factors of Valence and/or Extraversion/Neuroticism are reported below. 
To better capture the continuous nature of the trait construct, we further performed multiple linear regression models for each of the six regions of interests, with participants' extraversion scores and neuroticism scores as independent variables (i.e., predictors), and the ERP mean amplitude difference between conditions of interest as the dependent variables. The difference waves were computed by subtracting the mean amplitudes of neutral words from those of positive and negative words, respectively, and averaged within the same region of interests, in each time window as the ANOVA analyses. In total, 12 (2 Valence x 6 Regions) dependent variables were computed. Each dependent variable and the predictors were entered simultaneously in the model equation to determine which predictor was the most important, and how much variance of the dependent variable could be explained by a predictor independently from the other predictor in the equation.

\section{Results}

\section{Behavioral results}

Both words and pseudowords had similarly high mean accuracy (Word: $98.05 \% \pm 1.34 \%$, Pseudoword: $98.57 \% \pm 1.57 \%$, $t(37)=-0.744, p=0.461)$, indicating that participants followed instructions and did the required task.

The mean accuracies for words were further grouped according to different extraversion and neuroticism levels (Fig. $2)$. There was a main valence effect on accuracy rates $(F(2,68)$ $=5.596, p=0.011)$. Overall, participants were more accurate in recognizing positive stimuli $(98.6 \% \pm 0.3 \%)$ than neutral ones $(97.9 \% \pm 0.3 \%)$, with the lowest accuracy on negative stimuli (97.2\% $\pm 0.3 \%$ ) (positive vs. neutral: $p=0.04$; neutral vs. negative: $p=0.03$; negative vs. positive: $p=0.01$ ). No Extraversion/Neuroticism effects (both $F \mathrm{~s} \leq 2.15$ ) or other interactions (all $F \mathrm{~s} \leq 1$ ) were found.

\section{ERP results}

The grand averaged ERPs for valence effects for all participants are shown in Fig. 3. Apart from the visual N1 and P2 complex, the ERPs of the three experimental conditions (positive, negative, neutral) showed deflections starting from approximately $300 \mathrm{~ms}$ poststimulus, identified as N400s and late positivity components (LPCs). The grand averaged ERPs for valence effects for individuals with different levels of extraversion/neuroticism are plotted in Figs. 4, 5, 6, and 7. In terms of extraversion, the introverts started displaying more positive mean amplitudes in response to negative words than positive/neutral words at around $160 \mathrm{~ms}$ post-stimulus, with the effect most prominent at the frontal sites (Figs 4 and 5), whereas the extroverts did not show such a deflection. In

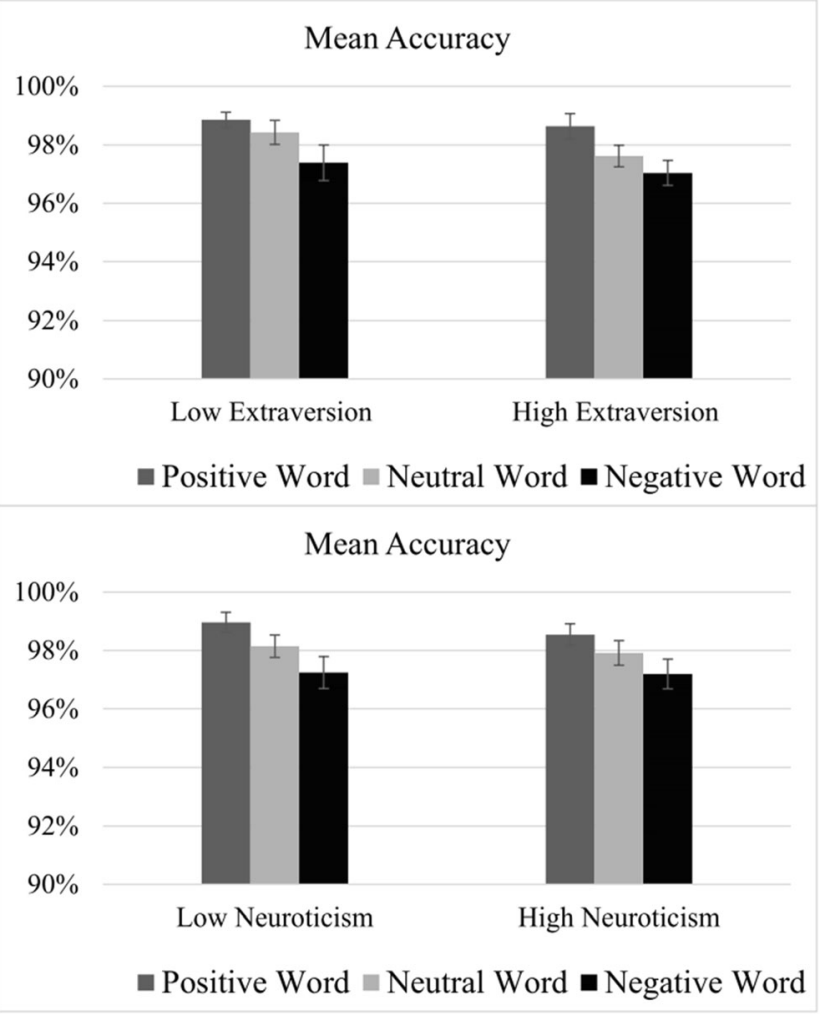

Fig. 2 Accuracy (in percentage) in each experimental condition for participants with different extraversion (top panel) and neuroticism (bottom panel) levels

terms of neuroticism, the high relative to low neurotics demonstrated larger ERP amplitudes to negative words than positive/neutral words around $200 \mathrm{~ms}$ post-stimulus, with a more left-lateralized distribution (Figs 6 and 7). The statistical results for the categorical (ANOVA) and continuous (regression) analyses are summarized in Tables 3 and 4 and detailed as follows:

\section{P2 (160-260 ms)}

The repeated-measures ANOVA revealed a trend of extraversion effect $\left(F(1,34)=3.777, p=0.06, \eta_{p}^{2}=0.1\right)$. The extroverts elicited a slightly larger P2 than did the introverts (extroverts: $6.722 \pm 0.728 \mathrm{uV}$; introverts: 4.72 $\pm 0.728 \mathrm{uV})$. There was a main effect of valence $(F(2$, 68) $\left.=12.578, p<0.001, \eta_{p}^{2}=0.27\right)$ and a valence $\mathrm{x}$ region interaction $\left(F(10,340)=3.705, p=0.014, \eta_{p}^{2}=\right.$ 0.098). The P2s were larger for neutral words $(6.154 \pm$ $0.572 \mathrm{uV})$ than positive $(5.303 \pm 0.501 \mathrm{uV})$ and negative words $(5.708 \pm 0.497 \mathrm{uV})$, regardless of the regions. The multiple regression model that included all the predictors and dependent variables showed no significant effect. 

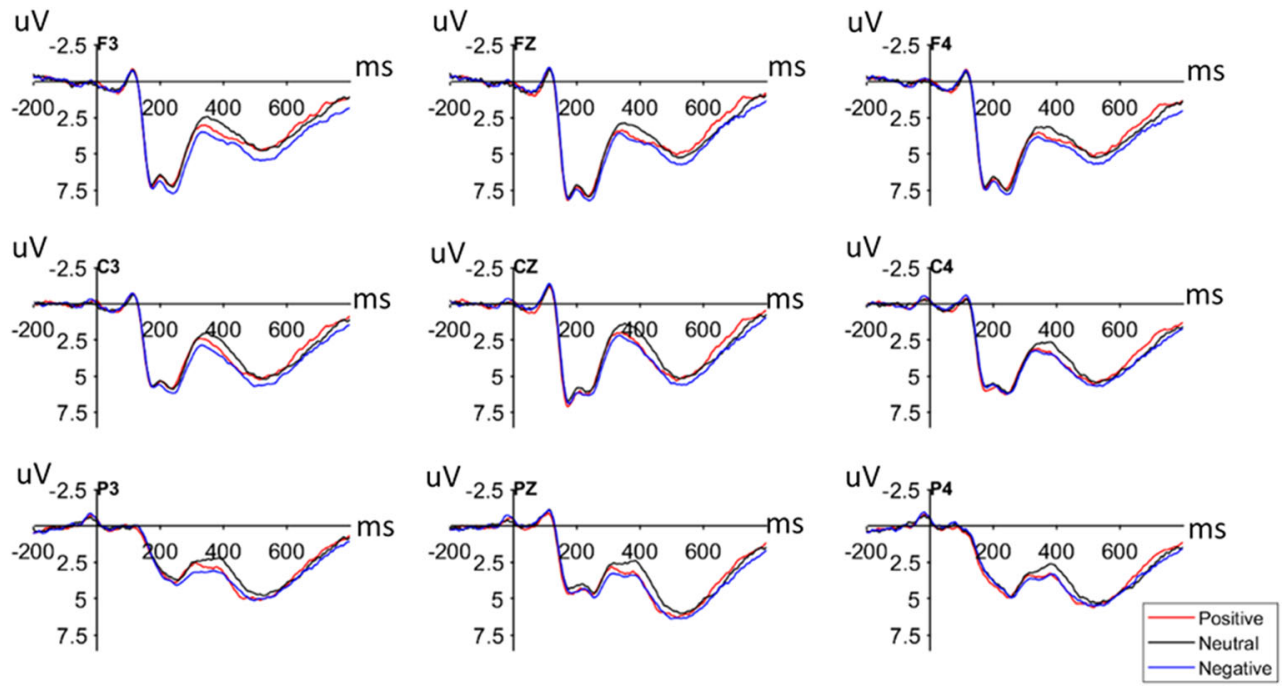

Fig. 3 Grand averaged ERPs for positive, neutral, and negative words at 9 representative electrodes

\section{N400 (300-450 ms)}

The repeated-measures ANOVA showed a main extraversion effect $\left(F(1,34)=4.851, p=0.035, \eta_{p}^{2}=0.125\right)$. The introverts showed more negative N400s to all the words than the extroverts (extroverts: $4.163 \pm 0.631 \mathrm{uV}$; introverts: $2.198 \pm 0.631$ $\mathrm{uV})$.

There was a main effect of valence $(F(2,68)=6.233, p=$ $\left.0.003, \eta_{p}^{2}=0.155\right)$. This means that in all the participants, the neutral words elicited larger N400s than the negative ones (neutral words: $2.944 \pm 0.497 \mathrm{uV}$; negative words: $3.504 \pm$ $0.457 \mathrm{uV})$. There was also a valence $\mathrm{x}$ region interaction $\left(F(10,300)=3.819, p=0.001, \eta_{p}^{2}=0.113\right)$. The valence effect came from the left sites and midline sites (left anterior: $F(2$, $74)=11.131, p<0.001, \eta_{p}^{2}=0.231$; left posterior: $F(2,74)=$ 8.024, $p=0.001, \eta_{p}^{2}=0.178$; mid-anterior: $F(2,74)=6.701, p$ $=0.002, \eta_{p}^{2}=0.153$; mid-posterior: $F(2,74)=6.730, p=$ $\left.0.002, \eta_{p}^{2}=0.154\right)$. Notably, at mid-posterior sites, the neutral words elicited larger N400 amplitudes than both the negative and positive words (positive words: $2.844 \pm 0.496 \mathrm{uV}$; neutral words: $2.22 \pm 0.521 \mathrm{uV}$; negative words: $3.01 \pm 0.503 \mathrm{uV}$ ).

In the multiple regression models that included both the predictors (Fig. 8), the extraversion and neuroticism scores jointly predicted the difference between the neutral and positive words at only the mid-anterior sites, albeit marginal after correction ( $\beta=0.397$ for extraversion, $\beta=0.542$ for neuroticism; adjusted R-square $=20.2 \%, F(2,35)=5.691, p=0.087$, uncorrected $p=0.007)$. Higher extraversion and neuroticism were associated with larger N400 effects for neutral relative to positive words. The two predictors showed low intercorrelations due to a lack of multicollinearity found between the extraversion and neuroticism scores (tolerance $=0.77$, Variance inflation factor $=1.298$ ), suggesting separate contribution from each of the traits for accounting for the variance.

\section{LPC (450-800 ms)}

The repeated-measures ANOVA showed that neuroticism interacted with valence $\left(F(2,68)=3.577, p=0.033, \eta_{p}^{2}=\right.$ $0.095)$ and with valence and region $(F(10,340)=2.532, p=$ $\left.0.045, \eta_{p}^{2}=0.069\right)$. In high neurotics, negative words elicited a larger LPC than the neutral and positive ones (positive words: 3.5 $\pm 0.48 \mathrm{uV}$; neutral words: $3.279 \pm 0.541 \mathrm{uV}$; negative words: 4.17 $\pm 0.576 \mathrm{uV})$, mainly coming from the left anterior sites $(F(2,36)$ $=12.322, p<0.001, \eta_{p}^{2}=0.406$; positive words: $3.533 \pm 0.515$ $\mathrm{uV}$; neutral words: $3.208 \pm 0.557 \mathrm{uV}$; negative words: $4.513 \pm$ $0.579 \mathrm{uV})$. In low neurotics, no valence effect was found.

There also was a main effect of valence $(F(2,68)=3.88, p=$ $\left.0.025, \eta_{p}^{2}=0.102\right)$ and a valence $\mathrm{x}$ region interaction $(F(10$, $340)=3.854, p=0.006, \eta_{p}^{2}=0.102$ ). Further comparison confirmed that negative words elicited a larger LPC than the neutral and positive ones at the left anterior sites only $(F(2,74)=8.679$, $p=0.001, \eta_{p}^{2}=0.190$; positive words: $3.428 \pm 0.37 \mathrm{uV}$; neutral words: $3.239 \pm 0.405 \mathrm{uV}$; negative words: $4.037 \pm 0.385 \mathrm{uV}$ ).

The multiple regression models that included both the predictors (Fig. 8) showed that only the extraversion scores predicted the difference amplitudes at the right anterior sites, albeit insignificant after correction $(\beta=-0.482$; adjusted R-square $=$ $20.4 \%, F(2,35)=5.746, p=0.083$, uncorrected $p=0.007)$. Participants' extraversion scores were negatively correlated with the LPC effect for negative relative to neutral words.

\section{Discussion}

The present study used ERP to investigate the influence of extraversion (i.e., extraverted or introverted) and neuroticism (i.e., high neurotic or low neurotic) on the visual recognition of emotional words. We found that personality traits mattered. 
a Extroverts
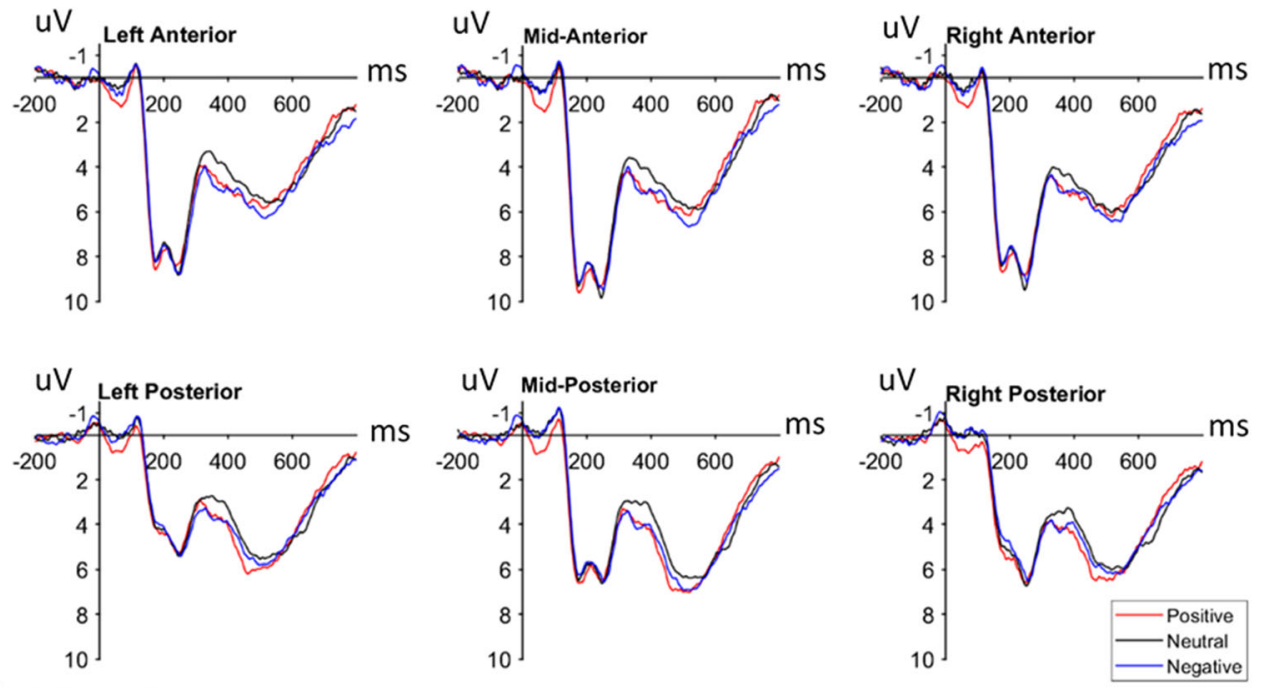

\section{b Introverts}
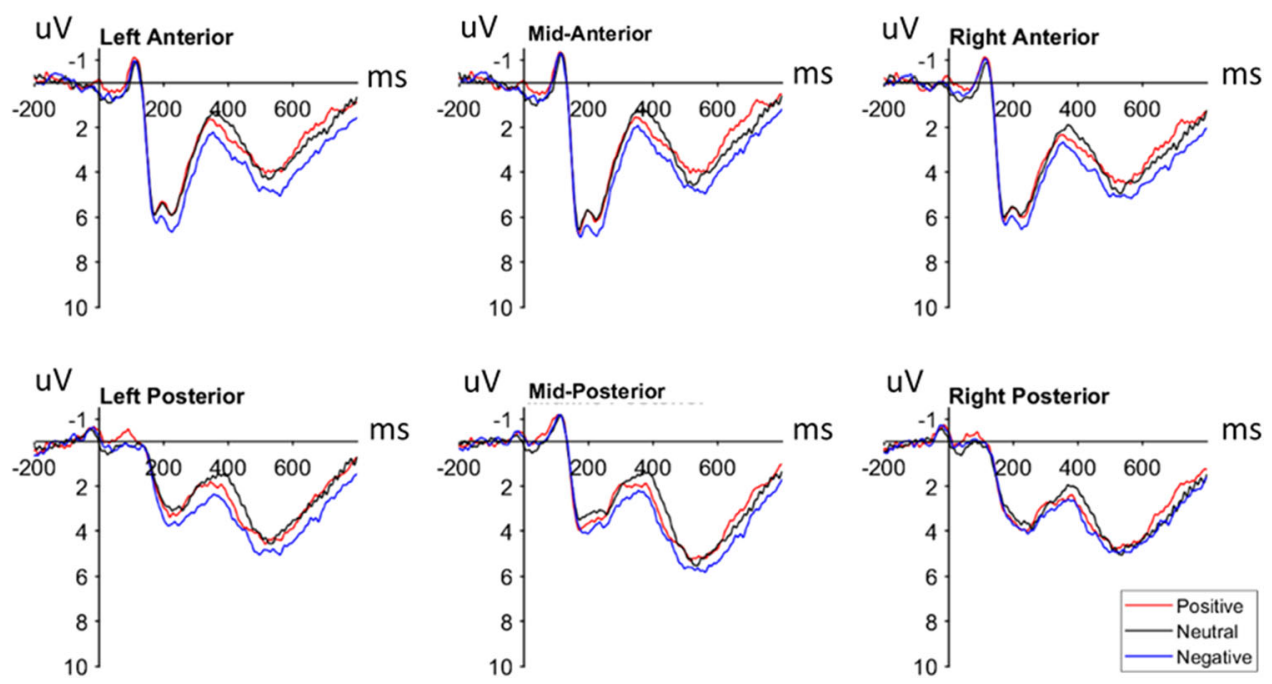

Fig. 4 Extroverts (Panel a) vs. Introverts (Panel b): Grand averaged ERP waveforms for positive (red line), neutral (black line), and negative (blue line) words at 6 regions (left anterior: F3, FC3; left posterior: CP3, P3;

In the P2 time frame, the extroverts showed a slightly larger P2 than the introverts, irrespective of word valence types. In the N400 time frame, the introverts had larger N400s than extroverts, irrespective of word valence types. The regression analysis revealed that the extroverts and high neurotics tended to have larger N400 effects for neutral relative to positive words at the mid-anterior sites, compared with the introverts and low neurotics. In the LPC time frame, the high neurotics showed larger LPC effects for negative relative to neutral and positive words at the left anterior sites. In the regression analysis, the introverts demonstrated slightly larger LPCs for negative words relative to neutral words at the right anterior sites, compared with the extroverts.

The larger P2s for all words in extroverts than in introverts indicated an early influence of extraversion on word mid-anterior: FZ, FCZ; mid-posterior: CPZ, PZ; right anterior: F4, FC4; and right posterior: $\mathrm{CP} 4, \mathrm{P} 4)$

processing. We associate the $\mathrm{P} 2$ with arousal factors. As discussed in the Introduction, the reticulothalamic-cortical arousal level is often heightened in extroverts but suppressed to a minimum in introverts. The high baseline arousal level likely captures attention, which led to the enhanced P2 (Carretié, Mercado, Tapia, \& Hinojosa, 2001; Yuan et al., 2012). We did not find an interaction between personality traits and word valence at the P2. The absence of such an interaction is likely due to the combination of different tasks (lexical decision vs. oddball task) and different stimulus modality (verbal vs. pictorial) employed between studies. Yuan et al. (2012) found that personality traits interacted with picture valence in the $\mathrm{P} 2$ time frame. They used a modified oddball task where participants made standard/deviant distinctions of pictures. They found a larger anterior P2 for emotional 


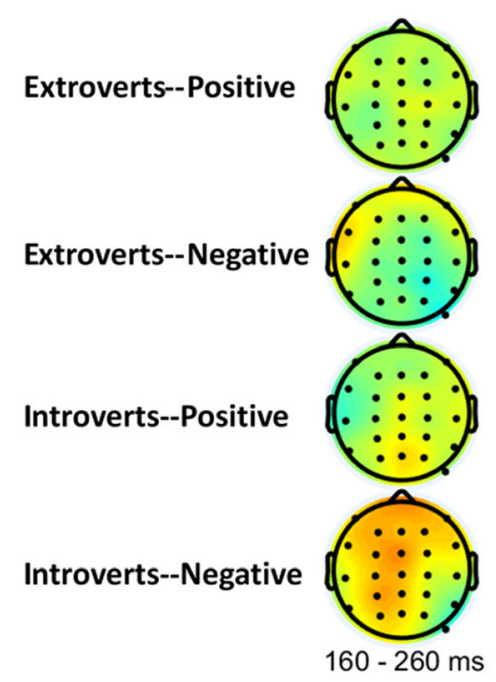

Fig. 5 Extroverts vs. Introverts: Topographies of the ERP difference waves for positive valence effects in extroverts (top row), negative valence effects in extroverts (second row from the top), positive valence

than for neutral pictures in extroverts, suggesting that extroverts allocate attention to emotional content early. An oddball task accentuates attention to the deviant more than a lexical decision task, which may have attenuated the personality trait modulation in this early time frame. Also, the arousal level of words might affect the earliness of the personality trait modulation. Both Yuan et al. (2012) and Sass et al. (2010) chose high arousing pictures or words (5-6 of 7 in pre-ratings), whereas we had to control for arousal between our conditions (3-4 of 7 in pre-ratings). Future research should test the hypothesis whether the higher arousing the stimuli are, the earlier the impact of a personality trait is.

The larger N400s for all words in introverts than in extroverts indicated an influence of extraversion on the processing of word semantics. Recent views of the N400 in language studies converge on the theory that the N400 reflects the ease of word retrieval from the semantic memory (Lau, Phillips, \& Poeppel, 2008). However, what leads to the ease of retrieval remains debated. It could be that it was easier for extroverts to retrieve a word as a whole. It also could be that it was easier for extroverts to retrieve an aspect of a word, such as the emotional valence, which then leads to facilitation of the whole word. Combined with the $\mathrm{P} 2$ results, we argue that the levels of word processing need to be taken into consideration. That is, the larger N400 effect might reflect a deeper, conceptual level of word processing in the introverts than in the extroverts.

Moreover, if we consider the regression results (trending at $p=0.083$ ), extraversion and neuroticism both came into play. Specifically, the more extraverted and neurotic the participants were, the more reduced the N400s for the positive words (relative to neutral words) were. The similarity of the result patterns between extraversion and neuroticism suggests a regroup of the participants into high versus low impulsivity groups. Based on Gray's biological theory of personality
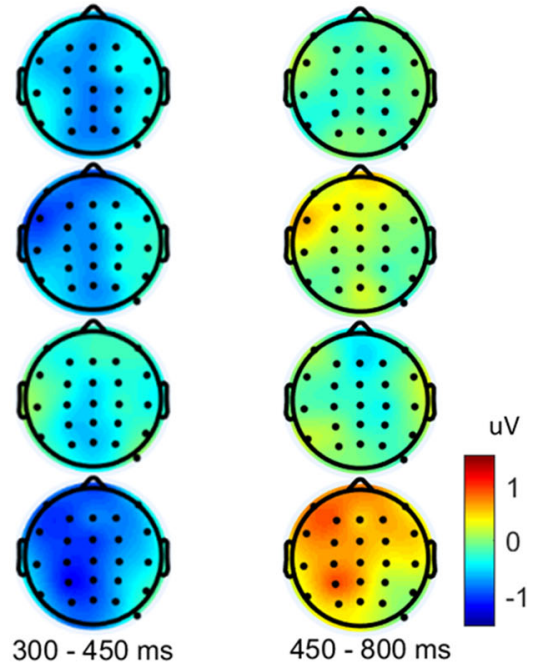

effects in introverts (third row from the top), and negative valence effects in introverts (bottom row)

(Gray, 1981), impulsivity is a spectrum spanning from a "high extraversion - high neuroticism" quadrant (termed high impulsivity) to a "low extraversion - low neuroticism" quadrant (termed low impulsivity). Impulsivity is characterized as novelty/sensation seeking, reward dependence, and harm avoidance. Partially supporting Gray's theory, our data demonstrated that the trait impulsivity, an indicator of a high behavioral activation system (BAS), leads to an ease of processing for positive information during the word recognition in the N400 time frame.

In addition to the similarity of the result patterns between extraversion and neuroticism, the anterior distribution of the N400 effect also supports the idea of regrouping based on impulsivity. Both extraversion and neuroticism modulate the $\mathrm{N} 400$ at the mid-anterior sites. The anteriority is consistent with one past ERP study examining the personality trait of impulsivity. De Pascalis, Arwari, D'Antuono, and Cacace (2009) reported that participants with higher trait impulsivity showed larger anterior/frontal N400s than those with lower impulsivity during emotional sentence processing. We thus postulate that for the high impulsivity group (i.e., high extraversion - high neuroticism) in our study, the anterior distribution of the reduced N400s reflects facilitated conceptual processing (cf., FN400, Kutas \& Federmeier, 2011), where prior experiences or the reward-seeking attributes make semantic processing of positive words easier. Alternatively, because previous studies indicated that impulsive people often show difficulty in processing complex information (De Pascalis et al., 2009; Harmon-Jones et al., 1997), the high impulsivity group might have more difficulty processing neutral words than positive ones, as neutral information often is less salient and more ambiguous/complex.

The influence of extraversion and neuroticism on emotional word recognition is further revealed in the LPC time frame. 
a High Neurotics
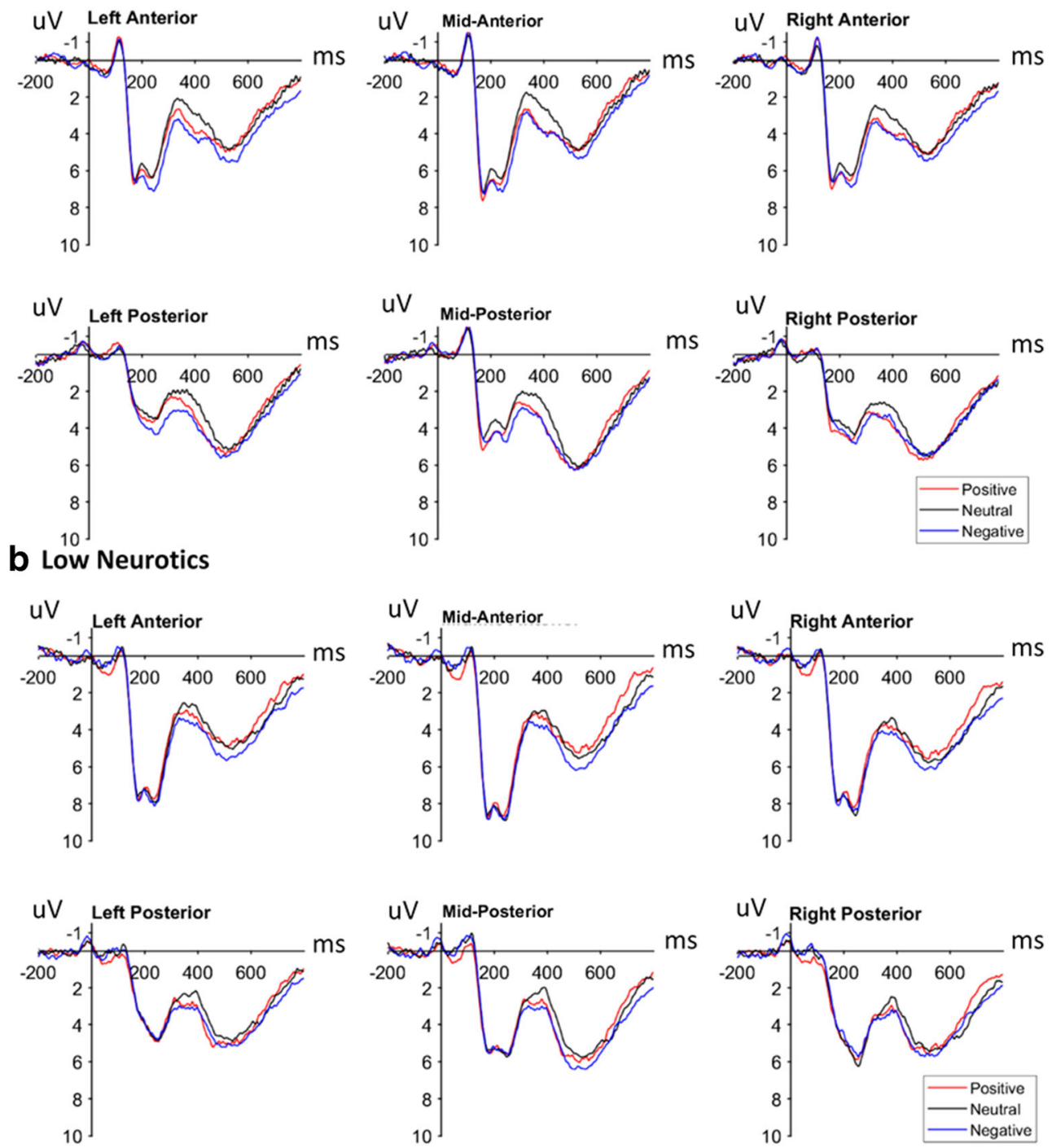

Fig. 6 High neurotics (Panel a) vs. Low neurotics (Panel b): Grand averaged ERP waveforms for positive (red line), neutral (black line), and negative (blue line) words at 6 regions (left anterior: F3, FC3; left

In both the high neurotic group (in the ANOVA analysis) and possibly the introverts (in the regression analysis), the negative words elicited a larger LPC than the neutral words. This suggests that the neurotics and introverts showed sustained attention and enhanced or elaborative processing of stimuli that they felt are particularly relevant to them. The similarity of the LPC result patterns between neuroticism and extraversion again suggests another re-group of the participants according to Gray's biological theory of personality (Gray, 1981): high vs. low anxiety. Anxiety is a spectrum spanning from a "low extraversion - high neuroticism" quadrant (termed high anxiety) to a "high extraversion - low neuroticism" quadrant (termed low anxiety) that is associated with the behavioral inhibition system (BIS). The finding that the high anxiety group had a "negativity bias" - the tendency to attend to negative meaning (cf., Introduction) - provides a posterior: $\mathrm{CP} 3, \mathrm{P} 3$; mid-anterior: $\mathrm{FZ}, \mathrm{FCZ}$; mid-posterior: $\mathrm{CPZ}$, PZ; right anterior: $\mathrm{F} 4, \mathrm{FC} 4$; and right posterior: $\mathrm{CP} 4, \mathrm{P} 4)$

potential explanation for the current debate regarding whether the LPC reflects a negativity bias or a positivity bias (see Citron, 2012 for a review).

We also found that there were differential scalp distributions of the LPC effects. As a broader family of P3 effects, these effects resemble P3a that reflects orienting responses and may involve involuntarily attentional allocation. In introverts, the LPC effects spread to the right frontal regions (in the regression analysis), whereas in high neurotics, the LPC effects were more prominent in the left frontal regions (in the ANOVA analysis). EEG literature has suggested that greater left or right frontal activity can be associated with trait tendencies to approach or withdraw from emotional stimuli (Coan \& Allen, 2004). Thus, the frontal LPC in introverts and high neurotics may reflect a task-dependent nature of LPCs. It is possible that our participants had varied motivational levels 


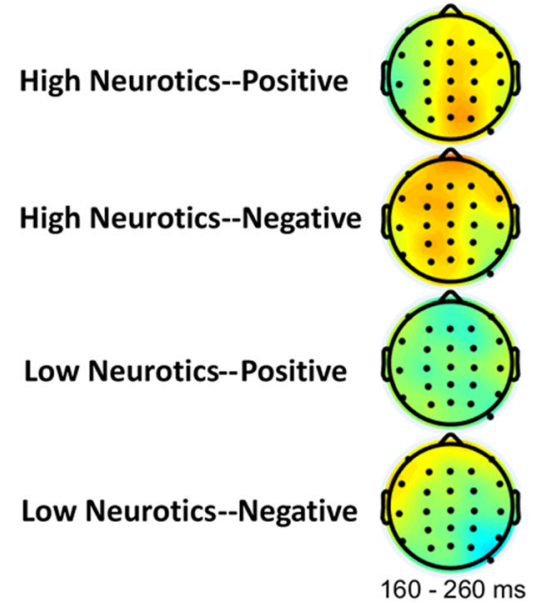

Fig. 7 High neurotics vs. Low neurotics: Topographies of the ERP difference waves for positive valence effects in high neurotics (top row), negative valence effects in high neurotics (second row from the

and appraisal styles, depending on the valence of the stimuli. Alternatively, the topographical differences may simply come from the categorical (ANOVA) and continuous (regression) analysis we conducted. Data were binned into categories in the former analysis, while kept as raw individual data in the latter. This could render different effect sensitivity shown in different scalp regions.

Our results revealed that there are two stages of personality impact on emotional word processing. In the earlier (N400) stage, emotional content is identified and conceptualized as a set of conceptual/semantic features in words (Hinojosa, Moreno, \& Ferré, 2019; Lindquist, 2013; Lindquist, MacCormack, \& Shablack, 2015). In this stage, the highly impulsive people (or extroverts and high neurotics) identified words with positive meaning. This means that in the high impulsivity group, the reward-seeking attribute, or the tendency to approach positive emotions, could facilitate the conceptualizing of positive emotional features in words. In the later (LPC) stage, emotional content is further attended to and processed elaboratively (Hofmann et al., 2009; Kanske \& Kotz, 2007; Schacht \& Sommer, 2009b). In this stage, the highly anxious people (or introverts and high neurotics) attended to words with negative meaning. An alternative interpretation for what happens in the later (LPC) stage is a simulation account, where the reason for an elaborative processing of emotional words is one's simulation of emotion experiences via episodic memory retrieval (Abbassi, Blanchette, Ansaldo, Ghassemzadeh, \& Joanette, 2015; Barsalou, 2009). For instance, LPC effects were associated with strategic mental simulation (i.e. mental imagery) activated by concrete emotional words (Kanske \& Kotz, 2007). This means that in this stage, introverts and high neurotics tended to be engaged, to some degree, in past experiences induced by negative information. Yet another interpretation for the later (LPC) stage is an appraisal account (Ellsworth \& Scherer, 2003; Roseman \& Smith, 2001).
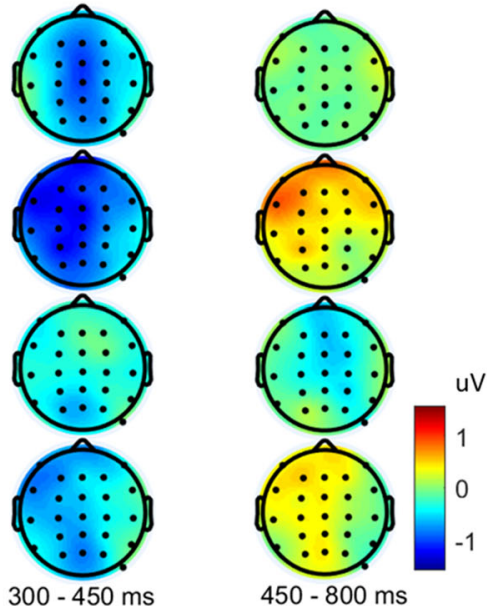

top), positive valence effects in low neurotics (third row from the top), and negative valence effects in low neurotics (bottom row)

Attenuated LPCs have been found in tasks where participants needed to make a non-affective judgment regarding the picture appraisal (Hajcak, Moser, \& Simons, 2006). In the current study, people with different personality traits might have different appraisal styles or causal attribution between a stimulus/ situation and emotion, leading to a bias (e.g., valence) in experiencing certain emotions. This means that introverts and high neurotics may be more biased to negative emotion appraisal, whereas extroverts and low neurotics may be more habitual in regulating or reappraising negative emotions using cognitive strategies.

Importantly, the current results appear to be more aligned with Gray's theory of personality traits, rather than Eysenck's earlier personality model. In Eysenck's model, extraversion and neuroticism are linked to positive and negative affect, respectively. However, our ERP data support a view in which extraversion and neuroticism may be combined in a certain way into traits impulsivity and anxiety. High behavioral activation system (BAS; high trait impulsivity group) is associated with positive emotions and is involved in the earlier stage of emotion word processing. In contrast, high behavioral inhibition system (BIS; high trait anxiety group) is associated with negative emotions and is involved in the later stage of emotion word processing. Note that we did not see a reversed pattern in low trait impulsivity (low extraversion, low neuroticism) or low trait anxiety (high extraversion, low neuroticism) group in response to words with the opposite valence in the N400 or LPC time frames. This may suggest that the low neurotics, regardless of their extraversion levels, processed the valence information unbiasedly. In addition, we found an earlier bias for positive valence processing (similar to the "positive offset" in P2 effects) than negative one (similar to the "negative bias" in LPC effects), dependent on personality traits. Future studies should address why the BAS influences emotional word processing earlier than the BIS. 
Table $3 \quad F$ values of the three-way repeated-measures ANOVAs in the time windows of $160-260 \mathrm{~ms}, 300-450 \mathrm{~ms}$, and $450-800 \mathrm{~ms}$

\begin{tabular}{llll}
\hline Variables & \multicolumn{2}{l}{ Time windows } \\
\cline { 2 - 4 } & $\begin{array}{l}160-260 \\
\mathrm{~ms}\end{array}$ & $\begin{array}{l}300-450 \\
\mathrm{~ms}\end{array}$ & $\begin{array}{l}450-800 \\
\mathrm{~ms}\end{array}$ \\
\hline Valence & $12.578^{* * *}$ & $6.233^{* *}$ & $3.880^{*}$ \\
Region & $63.156^{* * *}$ & $6.283^{* *}$ & 2.769 \\
Extraversion & 3.777 & $4.851^{*}$ & 0.206 \\
Neuroticism & 0.002 & 0.214 & 0.010 \\
Valence X Region & $3.705 *$ & $3.563 * *$ & $3.854^{* *}$ \\
Valence X Extraversion & 1.961 & 1.112 & 0.262 \\
Valence X Neuroticism & 0.291 & 1.195 & $3.577 *$ \\
Region X Extraversion & 0.397 & 0.978 & 2.530 \\
Region X Neuroticism & 1.016 & 0.905 & 1.557 \\
Extraversion X Neuroticism & 0.197 & 0.212 & 1.549 \\
Valence X Extraversion X & 0.537 & 0.090 & 1.457 \\
$\quad$ Neuroticism & & & \\
Valence X Region X Extraversion & 0.620 & 0.849 & 1.012 \\
Valence X Region X Neuroticism & 0.650 & 1.431 & $2.532 *$ \\
Region X Extraversion X & 1.390 & 1.313 & 1.364 \\
$\quad$ Neuroticism & & & \\
Valence X Region X Extraversion & 0.680 & 1.115 & 0.512 \\
$\quad$ X Neuroticism & & & \\
\hline$* p<0.05 ; * *<0.01 ; * * p<0.001$ & & \\
* $~$ & & &
\end{tabular}

Finally, our ERP data mostly replicated past research and showed that emotion effects occurred after 160 ms poststimulus (Kanske \& Kotz, 2007; Imbir et al., 2016). In the 160-260 ms time window, neutral words elicited a larger P2 than did both the positive and negative words. The results showed that emotional words and neutral words can capture attention differently early on. P2s have been found in studies not only when the incoming linguistic input is affectively salient, but also when it is unexpected in the experiment context
(Leuthold, Kunkel, Mackenzie, \& Filik, 2015). There are fewer neutral words than positive and negative words combined in our experiment context. The less frequent neutral words in our stimuli may override the affective salience of (relatively more) emotional words in early attention capture, leading to a larger P2 effect. In the 300-450 ms time window, neutral words elicited a greater $\mathrm{N} 400$ than did both positive and negative words at the mid-posterior sites. This shows that emotional words may cluster together as a group at some level regardless of their valence, which may be separate from neutral words, within the long-term memory. However, the subgrouping by valence still exists, as evidenced by its strong effect across all time windows and its interaction with personality traits in a later time window. As discussed above, words with positive connotations gained more prominence than negative ones in extroverts and high neurotics. This separates positive words from negative ones. In the $450-800 \mathrm{~ms}$ time window, negative words elicited a larger LPC than both positive and neutral words, implying a negativity bias usually seen in younger population. This LPC effect can reflect an enhanced attention towards negative information in general that could be modulated by personality traits as discussed above.

Although we replicated the valence effect, we did not find N1, P1, and/or EPN effects for emotional words relative to neutral words. There are several possibilities. First, past studies that reported early P1 or N1 effects often examined words with high frequency or high arousal level (Hofmann et al., 2009; Palazova et al., 2011; Scott et al., 2009). The current study did not use words with extreme frequency or valence. In addition, the lack of EPN effects may result from overlapping effect latencies elicited by our words that contain different parts of speech (verbs and nouns). For instance, the EPN was often found when processing adjectives and nouns (Herbert et al., 2008; Hinojosa et al., 2010; Kissler et al.,

Table 4 Summary of significant regression models in the time frames of 300-450 ms and 450-800 ms

\begin{tabular}{|c|c|c|c|c|c|c|}
\hline \multirow[t]{2}{*}{ Model } & & \multicolumn{2}{|c|}{ Unstandardized coefficients } & \multirow{2}{*}{$\begin{array}{l}\text { Standardized coefficients } \\
\text { Beta }\end{array}$} & \multirow[t]{2}{*}{$t$} & \multirow[t]{2}{*}{$p$} \\
\hline & & $\mathrm{B}$ & Std. Error & & & \\
\hline \multicolumn{7}{|c|}{ N400 (300-450 ms) } \\
\hline \multicolumn{7}{|c|}{ Mid-anterior } \\
\hline \multirow[t]{3}{*}{ Variables } & (Constant) & -1.505 & 0.666 & & -2.259 & 0.030 \\
\hline & Extraversion & 0.145 & 0.061 & 0.392 & 2.375 & 0.023 \\
\hline & Neuroticism & 0.208 & 0.064 & 0.542 & 3.241 & 0.003 \\
\hline \multicolumn{7}{|c|}{ LPC (450-800 ms) } \\
\hline \multicolumn{7}{|c|}{ Right anterior } \\
\hline \multirow[t]{3}{*}{ Variables } & (Constant) & 1.163 & 0.490 & & 2.347 & 0.023 \\
\hline & Extraversion & -0.129 & 0.045 & -0.482 & -3.432 & 0.007 \\
\hline & Neuroticism & 0.009 & 0.047 & 0.030 & 0.181 & 0.857 \\
\hline
\end{tabular}






Fig. 8 Correlation plots of personality trait scores and ERP amplitude differences. Left: The more extroverted and neurotics a participant is, the larger the N400 amplitude difference between positive words and

2009). According to Palazova et al. (2011), nouns and adjectives elicited EPN-like emotion effects approximately at the same time as the onset of the lexical effect $(\sim 270 \mathrm{~ms})$, while verbs' emotion effect came much later $(\sim 350 \mathrm{~ms})$. Alternatively, an EPN effect could be in disguise in our study: the $\mathrm{P} 2$ effect that we found might actually be a more widespread EPN with an opposite direction and polarity, given the similar effect latencies of the two effects. A final possibility for the lack of N1, P1, and/or EPN effects for emotional words relative to neutral words is that in word stimuli, the affective content of emotional words may not be accessed before the semantic content is retrieved (Abbassi et al., 2015; Barsalou, 2009; Hinojosa et al., 2010; Trauer, Kotz, \& Müller, 2015). In our lexical decision task, we oriented participants' attention toward the lexical aspect of the word stimuli instead of the affective aspect, leading to a later activation of affective content (cf. Lai et al., 2012).

There are limitations in the current study. First, the discrepancy between the continuous analysis (regression) and categorical analysis (ANOVA) suggests that continuous analyses may be more precise in accounting for variance in the ERP data than a categorical grouping for the participants (extroverts/introverts, high neurotics/low neurotics). Future studies need to consider the sensitivity of different analyses in understanding the personality impact on emotional word processing. Second, recruitment of a larger sample size of participants is expected to solidify conclusion towards the impact of personality traits on emotional word processing. Third, we used a mix of emotional words, including emotion-label words (e.g. happiness, sadness), and emotion-laden words (e.g. wedding, death). These categories may rely on different mechanisms and cortical regions. For instance, Zhang et al. (2014) found only negative emotion-label words elicited LPC amplitudes. Separating these categories can potentially uncover further influences of personality traits. Finally, a more ecological design with emotion narratives may extend our understanding of

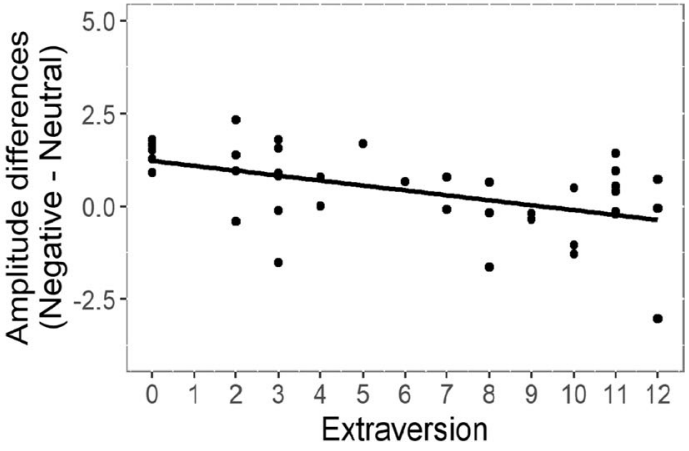

neutral ones is (at the mid-anterior sites). Right: The more introverted a participant is, the larger the LPC amplitude difference between negative words and neutral ones is (at the right anterior sites)

the interplay between personality traits and emotion processing, as contexts may provide readers with richer situated simulation and emotional experiences and can better differentiate the two processing stages discussed in this study.

\section{Conclusions}

The current study is one of the first neurophysiological reports to show that personality traits matter for the visual recognition of emotional words. High extraversion and high neuroticism orient people toward positive meaning conveyed by words early on, while low extraversion and high neuroticism orient people toward negative experiences later. Although the starting point of this paper and the grouping of the participants were based on traits extraversion and neuroticism in Eysenck's personality model, it appears that our data are better accounted for based on trait impulsivity and trait anxiety in Gray's personality theory.

Acknowledgments This research was supported by the Ministry of Science and Technology, Taiwan, R.O.C., under the Grant No. MOST 103-2410-H-003 -141 -MY3 to S.C. The authors thank the lab members of Neurolinguistics Lab in the Department of English, National Taiwan Normal University, for their assistance in data collection.

Open Practices Statements The data and materials for the experiment are available through the author Li-Chuan Ku (lchnku@gmail.com), and the experiment was not preregistered.

\section{References}

Abbassi, E., Blanchette, I., Ansaldo, A. I., Ghassemzadeh, H., \& Joanette, Y. (2015). Emotional words can be embodied or disembodied: the role of superficial vs. deep types of processing. Frontiers in psychology, 6, 975. 
Barsalou, L. W. (2009). Simulation, situated conceptualization, and prediction. Philosophical Transactions of the Royal Society B: Biological Sciences, 364(1521), 1281-1289.

Bartussek, D., Becker, G., Diedrich, O., Naumann, E., \& Maier, S. (1996). Extraversion, neuroticism, and event-related brain potentials in response to emotional stimuli. Personality and Individual Differences, 20(3), 301-312.

Beck, A. T., Ward, C. H., Mendelson, M., Mock, J., \& Erbaugh, J. (1961). An inventory for measuring depression. Archives of general psychiatry, 4(6), 561

Begleiter, H., \& Platz, A. (1969). Cortical evoked potentials to semantic stimuli. Psychophysiology, 6(1), 91-100.

Begleiter, H., Porjesz, B., \& Garozzo, R. (1979). Visual evoked potentials and affective ratings of semantic stimuli. In H. Begleiter (Ed.), Evoked brain potentials and behavior (pp. 127-141). Boston, MA: Springer.

Benjamini, Y., \& Hochberg, Y. (1995). Controlling the false discovery rate: a practical and powerful approach to multiple testing. Journal of the Royal Statistical Society. Series B (Methodological), 289- 300.

Bernat, E., Bunce, S., \& Shevrin, H. (2001). Event-related brain potentials differentiate positive and negative mood adjectives during both supraliminal and subliminal visual processing. International Journal of Psychophysiology, 42(1), 11-34.

Borkenau, P., Paelecke, M., \& Yu, R. (2010). Personality and lexical decision times for evaluative words. European Journal of Personality, 24(2), 123-136.

Canli, T. (2004). Functional brain mapping of extraversion and neuroticism: learning from individual differences in emotion processing. Journal of personality, 72(6), 1105-1132.

Canli, T., Zhao, Z., Desmond, J. E., Kang, E., Gross, J., \& Gabrieli, J. D. (2001). An fMRI study of personality influences on brain reactivity to emotional stimuli. Behavioral neuroscience, 115(1), 33.

Carretié, L., Mercado, F., Tapia, M., \& Hinojosa, J. A. (2001). Emotion, attention, and the 'negativity bias', studied through event-related potentials. International journal of psychophysiology, 41(1), 75-85.

Carretié, L., Hinojosa, J. A., Albert, J., López-Martín, S., De La Gandara, B. S., Igoa, J. M., \& Sotillo, M. (2008). Modulation of ongoing cognitive processes by emotionally intense words. Psychophysiology, 45(2), 188-196.

Cattell, R. B. (1965). The scientific analysis of personality. Baltimore, MD: Penguin Books.

Chen, K. J., Huang, C. R., Chang, L. P., \& Hsu, H. L. (1996). Sinica corpus: Design methodology for balanced corpora. In B.-S. Park \& J.-B. Kim (Eds.), Proceedings of the 11th Pacific Asia Conference on Language, Information and Computation (pp. 167-176). Seoul: Kyung Hee University.

Cho, S. L., Chen, H. C., \& Cheng, C. M. (2013). Taiwan corpora of Chinese emotions and relevant psychophysiological Data-A study on the norm of Chinese emotional words. Chinese Journal of Psychology, 55(4), 493-523.

Citron, F. M. (2012). Neural correlates of written emotion word processing: a review of recent electrophysiological and hemodynamic neuroimaging studies. Brain and language, 122(3), 211-226.

Citron, F. M., Weekes, B. S., \& Ferstl, E. C. (2013). Effects of valence and arousal on written word recognition: Time course and ERP correlates. Neuroscience letters, 533, 90-95.

Coan, J. A., \& Allen, J. J. (2004). Frontal EEG asymmetry as a moderator and mediator of emotion. Biological psychology, 67(1-2), 7-50.

Costa, P. T., \& McCrae, R. R. (1992). Normal personality assessment in clinical practice: The NEO Personality Inventory. Psychological assessment, 4(1), 5 .

De Pascalis, V., Arwari, B., D’Antuono, L., \& Cacace, I. (2009). Impulsivity and semantic/emotional processing: An examination of the N400 wave. Clinical Neurophysiology, 120(1), 85-92.
Delorme, A., \& Makeig, S. (2004). EEGLAB: an open source toolbox for analysis of single-trial EEG dynamics including independent component analysis. Journal of neuroscience methods, 134(1), 9-21.

DeYoung, C. G., Hirsh, J. B., Shane, M. S., Papademetris, X., Rajeevan, N., \& Gray, J. R. (2010). Testing predictions from personality neuroscience brain structure and the big five. Psychological Science, 21(6), 820-828.

Ellsworth, P. C., \& Scherer, K. R. (2003). Appraisal processes in emotion. In R. J. Davidson, K. R. Scherer, \& H. H. Goldsmith (Eds.), Series in affective science. Handbook of affective sciences (pp. 572-595). New York, NY: Oxford University Press

Eysenck, H. J. (1947). Dimensions of personality. New Brunswick: Transaction.

Eysenck, H. J. (1967). The biological basis of personality. Springfield, IL: Thomas.

Eysenck, H. J., \& Eysenck, M. W. (1985). Personality and individual differences: a natural science approach. New York, NY: Plenum Press.

Eysenck, S. B., Eysenck, H. J., \& Barrett, P. (1985). A revised version of the psychoticism scale. Personality and individual differences, 6(1), 21-29.

Gray, J. A. (1981). A critique of Eysenck's theory of personality. In H. J. Eysenck (Eds.), A model for personality (pp. 246-276). New York, NY: Springer.

Hajcak, G., Moser, J. S., \& Simons, R. F. (2006). Attending to affect: Appraisal strategies modulate the electrocortical response to arousing pictures. Emotion, 6(3), 517.

Harmon-Jones, E., Barratt, E. S., \& Wigg, C. (1997). Impulsiveness, aggression, reading, and the $\mathrm{P} 300$ of the event-related potential. Personality and individual differences, 22(4), 439-445.

Herbert, C., Kissler, J., Junghöfer, M., Peyk, P., \& Rockstroh, B. (2006). Processing of emotional adjectives: Evidence from startle EMG and ERPs. Psychophysiology, 43(2), 197-206.

Herbert, C., Junghofer, M., \& Kissler, J. (2008). Event related potentials to emotional adjectives during reading. Psychophysiology, 45(3), 487-498.

Hinojosa, J. A., Méndez-Bértolo, C., \& Pozo, M. A. (2010). Looking at emotional words is not the same as reading emotional words: Behavioral and neural correlates. Psychophysiology, 47(4), 748-757.

Hinojosa, J. A., Moreno, E. M., \& Ferré, P. (2019). Affective neurolinguistics: towards a framework for reconciling language and emotion. Language, Cognition and Neuroscience, 1-27.

Hofmann, M. J., Kuchinke, L., Tamm, S., Võ, M. L., \& Jacobs, A. M. (2009). Affective processing within 1/10th of a second: High arousal is necessary for early facilitative processing of negative but not positive words. Cognitive, Affective, \& Behavioral Neuroscience, 9(4), 389-397.

Huang, C. R. (2009). Tagged Chinese Gigaword Version 2.0. [Data file and code book]. Philadelphia: Lexical Data Consortium.

Huang, C. R., Kilgarriff, A., Wu, Y., Chiu, C. M., Smith, S., Rychly, P., ... \& Chen, K. J. (2005). Chinese Sketch Engine and the extraction of grammatical collocations. In Proceedings of the Fourth SIGHAN Workshop on Chinese Language Processing (pp. 48-55). Stroudsburg: ACL.

Huang, C. L., Chung, C. K., Hui, N., Lin, Y. C., Seih, Y. T., Lam, B. C. P., ... Pennebaker, J. W. (2012). The Development of the Chinese Linguistic Inquiry and Word Count Dictionary. Chinese Journal of Psychology, 54(2), 185-201.

Imbir, K. K., Spustek, T., \& Żygierewicz, J. (2016). Effects of valence and origin of emotions in word processing evidenced by event related potential correlates in a lexical decision task. Frontiers in psychology, 7, 271.

John, O. P., Naumann, L. P., \& Soto, C. J. (2008). Paradigm shift to the integrative Big-Five trait taxonomy: History, measurement, and conceptual issues. In O. P. John, R. W. Robins, \& L. A. Pervin (Eds.), 
Handbook of personality: Theory and research (3rd ed., pp. 114158). New York, NY: Guilford Press.

Kanske, P., \& Kotz, S. A. (2007). Concreteness in emotional words: ERP evidence from a hemifield study. Brain research, 1148, 138-148.

Kehoe, E. G., Toomey, J. M., Balsters, J. H., \& Bokde, A. L. (2012). Personality modulates the effects of emotional arousal and valence on brain activation. Social Cognitive and Affective Neuroscience, 7(7), 858-870.

Kissler, J., Assadollahi, R., \& Herbert, C. (2006). Emotional and semantic networks in visual word processing: insights from ERP studies. Progress in brain research, 156, 147-183.

Kissler, J., Herbert, C., Winkler, I., \& Junghofer, M. (2009). Emotion and attention in visual word processing-An ERP study. Biological psychology, 80(1), 75-83.

Kutas, M., \& Federmeier, K. D. (2011). Thirty years and counting: finding meaning in the N400 component of the event-related brain potential (ERP). Annual review of psychology, 62, 621-647.

Lai, V. T., Hagoort, P., \& Casasanto, D. (2012). Affective primacy vs. cognitive primacy: Dissolving the debate. Frontiers in psychology, $3,243$.

Lau, E. F., Phillips, C., \& Poeppel, D. (2008). A cortical network for semantics: (De)constructing the N400. Nature Reviews Neuroscience, 9, 920-933.

LeDoux, J. (2003). The emotional brain, fear, and the amygdala. Cellular and molecular neurobiology, 23(4-5), 727-738.

Leuthold, H., Kunkel, A., Mackenzie, I. G., \& Filik, R. (2015). Online processing of moral transgressions: ERP evidence for spontaneous evaluation. Social cognitive and affective neuroscience, 10(8), 10211029.

Lindquist, K. A. (2013). Emotions emerge from more basic psychological ingredients: A modern psychological constructionist model. Emotion Review, 5(4), 356-368

Lindquist, K. A., MacCormack, J. K., \& Shablack, H. (2015). The role of language in emotion: Predictions from psychological constructionism. Frontiers in Psychology, 6, 444

Lopez-Calderon, J., \& Luck, S. J. (2014). ERPLAB: An open-source toolbox for the analysis of event-related potentials. Frontiers in human neuroscience, 8,213

Lu, M.-L., Che, H.-H., Chang, S.-W., Shen, W. W. (2002). Reliability and Validity of the Chinese Version of the Beck Depression Inventory-II. Taiwanese Journal of Psychiatry, 16(4), 301-310.

Matthews, G., Pitcaithly, D., \& Mann, R. L. (1995). Mood, neuroticism, and the encoding of affective words. Cognitive Therapy and Research, 19(5), 563-587.

Morris, L. W. (1979). Extraversion and introversion: An interactional perspective. Washington, DC: Hemisphere Publishing Corporation.

Palazova, M., Mantwill, K., Sommer, W., \& Schacht, A. (2011). Are effects of emotion in single words non-lexical? Evidence from event-related brain potentials. Neuropsychologia, 49(9), 2766-2775.

Pennebaker, J. W., \& King, L. A. (1999). Linguistic styles: Language use as an individual difference. Journal of personality and social psychology, 77(6), 1296.

Pivik, R. T., Broughton, R. J., Coppola, R., Davidson, R. J., Fox, N., \& Nuwer, M. R. (1993). Guidelines for the recording and quantitative analysis of electroencephalographic activity in research contexts. Psychophysiology, 30(6), 547-558.
Recio, G., Conrad, M., Hansen, L. B., \& Jacobs, A. M. (2014). On pleasure and thrill: the interplay between arousal and valence during visual word recognition. Brain and language, 134, 34-43.

Roseman, I. J., \& Smith, C. A. (2001). Appraisal theory: Overview, assumptions, varieties, controversies. In K. R. Scherer, A. Schorr, \& T. Johnstone (Eds.), Appraisal processes in emotion: Theory, methods, research (pp. 3-19). New York, NY: Oxford University Press.

Sass, S. M., Heller, W., Stewart, J. L., Silton, R. L., Edgar, J. C., Fisher, J. E., \& Miller, G. A. (2010). Time course of attentional bias in anxiety: emotion and gender specificity. Psychophysiology, 47(2), 247259.

Schacht, A., \& Sommer, W. (2009a). Emotions in word and face processing: early and late cortical responses. Brain and cognition, 69(3), 538-550.

Schacht, A., \& Sommer, W. (2009b). Time course and task dependence of emotion effects in word processing. Cognitive, Affective, \& Behavioral Neuroscience, 9(1), 28-43.

Schapkin, S. A., Gusev, A. N., \& Kuhl, J. (2000). Categorization of unilaterally presented emotional words: an ERP analysis. Acta neurobiologiae experimentalis, 60(1), 17-28.

Scott, G. G., O’Donnell, P. J., Leuthold, H., \& Sereno, S. C. (2009). Early emotion word processing: Evidence from event-related potentials. Biological psychology, 80(1), 95-104.

Speed, B. C., Nelson, B. D., Perlman, G., Klein, D. N., Kotov, R., \& Hajcak, G. (2015). Personality and emotional processing: A relationship between extraversion and the late positive potential in adolescence. Psychophysiology, 52(8), 1039-1047.

Trauer, S. M., Kotz, S. A., \& Müller, M. M. (2015). Emotional words facilitate lexical but not early visual processing. BMC neuroscience, 16(1), 89.

Watson, D., \& Clark, L. A. (1997). Extraversion and its positive emotional core. In R. Hogan, J. Johnson, \& S. Briggs (Eds.), Handbook of personality psychology (pp. 767-793). San Diego, CA: Academic Press.

Watson, D., Clark, L. A., \& Harkness, A. R. (1994). Structures of personality and their relevance to psychopathology. Journal of abnormal psychology, 103(1), 18.

Wood, A., Lupyan, G., \& Niedenthal, P. (2016). Why do we need emotion words in the first place? Commentary on Lakoff (2015). Emotion Review, 8(3), 274-275.

Wright, C. I., Williams, D., Feczko, E., Barrett, L. F., Dickerson, B. C., Schwartz, C. E., \& Wedig, M. M. (2006). Neuroanatomical correlates of extraversion and neuroticism. Cerebral Cortex, 16(12), $1809-1819$

Yuan, J., Zhang, J., Zhou, X., Yang, J., Meng, X., Zhang, Q., \& Li, H. (2012). Neural mechanisms underlying the higher levels of subjective well-being in extraverts: Pleasant bias and unpleasant resistance. Cognitive, Affective, \& Behavioral Neuroscience, 12(1), 175-192.

Zhang, D., He, W., Wang, T., Luo, W., Zhu, X., Gu, R., ... \& Luo, Y. J. (2014). Three stages of emotional word processing: an ERP study with rapid serial visual presentation. Social cognitive and affective neuroscience, 9(12), 1897-1903.

Publisher's note Springer Nature remains neutral with regard to jurisdictional claims in published maps and institutional affiliations. 